УДК 528.44

DOI: $10.33764 / 2687-041 X-2021-2-135-141$

\title{
ПРОБЛЕМЫ ГЕОДЕЗИЧЕСКОЙ ОСНОВЫ КАДАСТРА
}

\section{Елизавета Константиновна Костенко}

Сибирский государственный университет геосистем и технологий, 630108, Россия, г. Новосибирск, ул. Плахотного, 10, обучающийся, тел. (950)267-77-33, e-mail: loplzxc@mail.ru

\section{Олеся Игоревна Мальгина}

Сибирский государственный университет геосистем и технологий, 630108, Россия, г. Новосибирск, ул. Плахотного, 10, кандидат технических наук, доцент кафедры кадастра и территориального планирования, тел. (913)000-13-32, e-mail: 131379@mail.ru

В условиях современных темпов развития государства, значительно увеличивается необходимость в получении достоверных и оперативных сведений, используемых в кадастровой деятельности. Единый государственный реестр недвижимости в настоящее время это сводный системный элемент данных о недвижимом имуществе, земельных участках, границах субъектов, муниципальных образований, населённых пунктах. Для реализации целей государственного кадастра необходимы сведения о местоположении границ участков, площади этих объектов. Приобретение тех или иных сведений не представляется возможным без проведения измерительных геодезических работ. В целях организации ведения единого государственного реестра недвижимости в кадастре используются определенные правила в отношении кадастровых округов и местных систем координат. Геодезической основой кадастра являются государственная геодезическая сеть и геодезические сети специального назначения. Данные правила позволяют получать точные данные об исследуемом объекте, сокращать количество ошибок в реестре и обеспечить оперативной информацией потребителя таких данных.

Ключевые слова: кадастровая деятельность, государственная геодезическая сеть, опорная межевая сеть, системы координат, недвижимое имущество

\section{PROBLEMS OF GEODETIC FOUNDATIONS OF THE CADASTRE}

\section{Elizabeth K. Kostenko}

Siberian State University of Geosystems and Technologies, 10, Plakhotnogo St., Novosibirsk, 630108, Russia, Student, phone: (950)267-77-33, e-mail: loplzxc@mail.ru

\section{Olesya I. Malygina}

Siberian State University of Geosystems and Technologies, 10, Plakhotnogo St., Novosibirsk, 630108, Russia, Ph. D., Associate Professor, Department of Cadastre and Territorial Planning, phone: (913)000-13-32, e-mail: 131379@mail.ru

In the conditions of modern rates of development of the state, the need to obtain reliable and operational information used in cadastral activities is significantly increasing. The Unified State Register of Real Estate is currently a consolidated system element of data on real estate, land plots, borders, municipalities, and localities. To implement the goals of the state cadastre, one needs information about the location of the boundaries of land plots and the area of these objects. The acquisition of certain information is not possible without carrying out geodetic works. In order to organize the maintenance of the Unified State Register of Real Estate, the cadastre uses the local coordinate systems defined in relation to cadastral districts. The geodetic basis of the cadastre is the state geodetic network and special-purpose geodetic networks. These parameters allow getting accurate data about the object under study, reduce the number of errors in the registry, and provide operational information to the consumer of such data. 
Keywords: cadastral activities, state geodetic network, reference boundary network, coordinate systems, real estate

Для осуществления и реализации поставленных целей и задач кадастровая деятельность основывается на данных, позволяющих однозначно идентифицировать территориальные субъекты и недвижимое имущество.

Для получения этих сведений необходимо проведение соответствующих геодезических измерений на местности. На геодезических измерениях базируются основные измерительные работы для определения параметров кадастра.

В настоящее время кадастровая деятельность для государства имеет следующие цели:

- обеспечение гарантированными правами на недвижимость;

- создание налогооблагаемой базы для имущественного и земельного налогов;

- обеспечение получения субъектами Российской Федерации и муниципальными образованиями информации, которая необходима в целях повышения эффективности территориального планирования.

Понятие площади объекта и характеристика местоположения в кадастровой деятельности являются основными сведениями о параметрах этих участках. Определить площадь, описать местоположение кадастрового объекта возможно при условии проведения геодезических измерений [11].

Определение местоположения для объектов незавершённого строительства, зданий, сооружений и иных строений, а также земельных участков и территориальных границ муниципальных образований осуществляется с помощью координат характерных точек этих объектов. Данные координаты определяются, в основном, геодезическими методами.

Касаемо площади объектов, в данном случае, необходимо вычислить геодезическую площадь, что представляет собой определение площади по геодезическим координатам углов межевых знаков, то есть поворотных точек, границ исследуемых участков.

Геодезическая основа ЕГРН регулируется федеральными законами, нормативно-правовыми актами органов законодательной и исполнительной власти [9]. Согласно законам, нормативно-правовым актам органов исполнительной власти, геодезической основой является государственная геодезическая сеть и геодезические сети специального назначения (межевые сети). Межевые сети нужно классифицировать по точности и назначению на опорные межевые сети и межевые съёмочные сети.

В настоящее время, законодательство в сфере геодезии и картографии регулярно подвергается обновлению, в связи с усовершенствованием систем и способов геодезических исследований [6]. Новая или обновлённая геодезическая основа кадастра подлежит внесению в единый государственный реестр недвижимости.

Государственной геодезической сетью признаётся обобщённость определённых геодезических пунктов, одинаково расположенных по всей территории. Данные пункты обычно определены на местности специализированными 
центрами, которые смогут обеспечить сохранность, устойчивость, целостность в плане и по высоте на долгий промежуток времени [14].

На территории, где точность и плотность геодезических сетей не соответствует законодательно установленным техническим составляющим ведения ЕГРН, создаются специальные геодезические сети. Специальными геодезическими сетями называются опорные межевые сети, создаваемые согласно утверждённому соответствующим постановлением Правительства Российской Федерации [3].

Опорные межевые сети необходимы в целях выявления единой основы координат на местах кадастровых округов для организации ведения кадастрового учёта объектов недвижимости, государственного реестра земельных участков кадастрового округа или района, постоянной аналитики, непрерывного анализа земель, земельных информационных подсистем.

Опорная межевая сеть позволяет определить точную геодезическую основу систем землевладения, землепользования и межевания земельных участков, в том числе инвентаризации земель различного значения [13].

Одной из главных целей в современном обществе признаётся максимально возможное сохранение природных ресурсов и их рациональное распределение. Опорные межевые сети используют и в целях разработки комплекса мероприятий, направленного на сохранение природных ландшафтов, и защиты природных ресурсов от неблагоприятной среды путём закрепления границ этих участков.

Для кадастровой деятельности также используются геодезические сети сгущения. Геодезические сети сгущения создаются для увеличения в будущем плотности государственной геодезической сети высшего порядка.

Геодезические сети сгущения подразделяются на плановые, которые создаются с помощью использования методов полигонометрии, триангуляции и трилатерации первых и вторых разрядов, и высотные, которые создаются посредством использования методов технического нивелирования [19].

Кадастровая деятельность сопровождается использованием систем координат, которые часто приводят к возникновению таких проблем, как отсутствие единой закономерности при определении характеристик конвертирования систем координат [2]. Это может привести к наложению границ земельных участков или разрыву у смежных участков земли.

Проводя анализ местных систем координат, можно отметить следующие основные недостатки:

- низкая точность опорных геодезических сетей, исключение из которых составляют сети, созданные с использованием глобальных навигационных спутниковых систем;

- ограниченное использование современных спутниковых технологий при построении местных систем координат.

Связано это с тем, что каждый кадастровый округ может использовать в своей кадастровой деятельности различные системы координат [15]. Таким образом, в каждом кадастровом округе определяется основная система координат, 
в дальнейшем на основе выбранной системы координат ведётся дежурный кадастровый план территории.

Выбор системы координат должен быть обоснован, характерен для территории кадастрового округа и отвечать нормам и стандартам, установленным соответствующим нормативным положением.

При введении местной системы координат необходимо соблюдать возможность перехода от местной системы координат к государственной системе координат.

Весомое значение в кадастровой деятельности определяют геодезические работы [16]. Характер геодезических работ формируется от направленности кадастровых работ, в том числе степени ее автоматизации. Однако в ряде случаев работа проводится по нижеизложенному алгоритму.

В первую очередь проводятся подготовительные работы, которые представляют собой сбор и анализ данных:

- проект землеустройства; постановление органа власти об отделении конкретного земельного участка;

- договор купли-продажи, либо договор аренды земельного участка;

- сведения о землях;

- чертёж границ земельного участка и далее по перечню необходимых документов для проведения геодезических работ.

Вторым этапом является полевое исследование пунктов опорной геодезической сети. На данном этапе определяют наиболее выгодную технологию проведения геодезических работ и осуществляется проверка сохранности пунктов.

На третьем этапе составляется технический проект, включающий в себя текстовую часть, графические материалы, смету расходов и затрат [4]. Геодезические работы всегда выполняются по заранее составленному техническому плану, проекту.

На четвертом этапе исходя из назначения кадастровых работ, производятся кадастровые съёмки в тех же масштабах и аналогичными способами, что и топографические съёмки [21]. Но на кадастровых планах дополнительно изображаются границы земельных участков, кадастровые номера, также описывают категории использования земель и остальные кадастровые сведения.

Пятым этапом является установление и согласование границ земли на местности. На данном этапе устанавливаются границы земельных участков на местности с помощью использования координат характерных точек от пунктов геодезического основания и данные границы закрепляются специализированными межевыми знаками [10]. Для согласования границ земельного участка привлекаются владельцы, пользователи данным земельным участком и участков, смежных с ним, а также представитель органов государственной власти.

После согласования границ земельного участка, определяется его площадь. Площадь земельного участка определяется, чаще всего, по координатам межевых знаков с использованием аналитического метода. Иногда, при вычислении площади земельного участка, используются картографические материалы [7]. Определив площадь, составляется чертёж границ, который составляется в масштабе 
основного кадастрового плана по результатам установления на местности и согласования границ земельного участка.

Заключительным этапом проведения геодезических работ является контроль и регистрация результатов кадастровой деятельности [5]. Посредством применения контрольных мероприятий на этапе работ устраняются допущенные ошибки, несогласованности, которые могут возникнуть в процессе съёмок, одновременно осуществляется контроль над соблюдением правил и требований технического получения и соответствующих инструкций по проведению топографических геодезических работ [18].

Результаты проводимых работ подлежат включению в специальный реестр и отображаются на кадастровых картах и планах. В целях системности и эффективности управления большими объёмами графической, текстовой информации необходимо создание базы данных. Помимо хранения информации, базы данных оперативно выдают нужную информацию.

В настоящее время возможности в сфере геодезии настолько широки, что позволяют точно измерить расстояние между зданиями, строениями, определить границы территориальных образований, границ между районами, областями [1].

Основной задачей специалиста является вычисление координат характерных точек местности путём проведения геодезической съёмки, обработка полученных данных, анализ и составление проекта или плана.

Геодезические материалы и сведения об объектах недвижимости основополагающие данные, необходимые для ведения ЕГРН [17]. Данные материалы и сведения представляют собой информацию о значениях геодезических координат характерных точек, которые позволяют описывать точки пространственного положения объекта недвижимости.

Геодезические данные об объекте являются уникальными и точно определяют такие сведения, как местоположение объекта, ориентацию, конфигурацию [12]. Геодезические данные являются достоверным источником наличия или отсутствия возможных ошибок и основанием для исправления и недопущения кадастровых ошибок.

В современном мире, с использованием геодезических данных оценивается и прогнозируется будущее состояние территорий в пространственном отношении под влиянием, оказываемым деятельностью людей, посредством создания модели пространственной составляющей территориального объекта, также обрабатывается большой объём информации и временных состояний.

В геодезическом информационном обеспечении сейчас фокус перемещается со сбора данных об объекте на их обработку, анализ, интерпретацию и представление [20]. Около 70 \% всех управленческих решений, которые принимает тот или иной орган государственной власти, носят пространственный характер и базируются на пространственно координированной информации.

Геодезические работы в кадастровой деятельности являются основой и важным инструментом для получения точной, обоснованной и достоверной информации о характеристиках объектов. Данные работы необходимы для точной привязки недвижимого объекта на участке какой-либо земли, для создания 
межевого плана, моделирования цифровой и трёхмерной модели местности и других работ [8]. Кадастровые и геодезические работы проводятся с целью однозначного определения прохождения границ земельных участков на определенной территории и подготовки соответствующих документов, определения площади недвижимости.

\section{БИБЛИОГРАФИЧЕСКИЙ СПИСОК}

1. Абезин, Д. В. Скрипкин. - 2-е изд., испр. и доп. - Москва: Издательство Юрайт, 2019. $144 \mathrm{c}$.

2. Багратуни Г. В. Инженерная геодезия: Учебник для вузов/Багратуни Г. В., Ганьшин В. И., Данилевич Б. Б. и др. 3-е изд., перераб. и доп. М., Недра, 2018. - 344 с.

3. Базавлук, В. А. Инженерное обустройство территорий. Мелиорация: учебное пособие для прикладного бакалавриата / В. А. Базавлук. - Москва: Издательство Юрайт, 2019. - 139 с.

4. Васильева, Н. В. Основы землепользования и землеустройства: учебник и практикум для академического бакалавриата/ Н. В. Васильева. - Москва: Издательство Юрайт, 2019. $376 \mathrm{c}$.

5. Вострокнутов, А. Л. Основы топографии: учебник для среднего профессионального образования / А. Л. Вострокнутов, В. Н. Супрун, Г. В. Шевченко; под общей редакцией А. Л. Вострокнутова. - Москва: Издательство Юрайт, 2019. - 196 с.

6. Дементьев В. Е. Современная геодезическая техника и ее применения: Учебное пособие для вузов. - Изд. 2-е. - М.: Академический Проект, 2018. - 591 с.

7. Елисеев С. В. Геодезические инструменты и приборы. Основы расчета, конструкции и особенности изготовления. Изд. 3-е, перераб. и дон. М., «Недра», 2017. - 645 с.

8. Емельянова, Л. Г. Биогеографическое картографирование: учебное пособие для академического бакалавриата / Л. Г. Емельянова, Г. Н. Огуреева. - 2-е изд., испр. и доп. - Москва: Издательство Юрайт, 2019. - 108 с.

9. Захаров А. И. Геодезические приборы: Справочник. - М.: Недра, 2017. - 314 с.

10. Кочетова Э. Ф. Инженерная геодезия: Учебное пособие. - Нижний Новгород: ННГАСУ, 2012.-153 с.

11. Макаров, К. Н. Инженерная геодезия: учебник для среднего профессионального образования / К. Н. Макаров. - 2-е изд., испр. и доп. - Москва: Издательство Юрайт, 2019. $243 \mathrm{c}$. $598 \mathrm{c}$.

12. Маслов А. В., Гордеев А. В., Батраков Ю. Г. Геодезия. - М.: КолосС, 2016. -

13. Нестеренок, М.С. Геодезия Учебное пособие для студентов специальности 1-510201 «Разработка месторождений полезных ископаемых (по направлениям)» / М.С. Нестеренок. Мн.: БНТУ, 2018. - 296 с.

14. Огуреева, Г. Н. Экологическое картографирование: учебное пособие для академического бакалавриата / Г. Н. Огуреева, Т. В. Котова, Л. Г. Емельянова. - 2-е изд., испр. и доп. Москва: Издательство Юрайт, 2019. - 162 с.

15. Плотников В.С. Геодезические приборы: Учебник для вузов. - М.: Недра, 2016. $396 \mathrm{c}$.

16. Поклад Г.Г. Геодезия: учебное пособие для вузов/ Г.Г. Поклад, С.П. Гриднев. - М.: Академический Проект, 2017. - 592 с. 13. В. Н. Попов, С. И. Чекалин. Геодезия: Учебник для вузов. - М.: «Горная книга», 2017. - 201 с.

17. Пылаева, А. В. Модели и методы кадастровой оценки недвижимости: учебное пособие для среднего профессионального образования / А. В. Пылаева. - 2-е изд., испр. и доп. Москва: Издательство Юрайт, 2019. - 153 с. 
18. Сабо, Е. Д. Гидротехнические мелиорации: учебник для среднего профессионального образования / Е. Д. Сабо, В. С. Теодоронский, А. А. Золотаревский ; под общей редакцией Е. Д. Сабо. - 2-е изд., испр. и доп. - Москва: Издательство Юрайт, 2019. - 317 с.

19. Цепляев, А. Н. Машины и оборудование для природообустройства и водопользования: учебное пособие для среднего профессионального образования / А. Н. Цепляев, В. Г.

20. Чекмарев, А. А. Начертательная геометрия и черчение: учебник для среднего профессионального образования / А. А.Чекмарев. - 7-е изд., испр. и доп. - Москва: Издательство Юрайт, 2019. - 423 с.

21. Шилов., П. И. Геодезия / П.И. Шилов. - М.: Госгеолтехиздат, 2017. - 384 с.

(C) Е. К. Костенко, О. И. Мальгина, 2021 